Vol. 119, No. 1, 1984

February 29, 1984
BIOCHEMICAL AND BIOPHYSICAL RESEARCH COMMUNICATIONS

Pages $42-48$

\title{
AFFINITY ISOLATION OF RNA POLYMERASE II ON AMANITIN-SEPHAROSE
}

\author{
Leonard C. LUTTER ${ }^{*}$ and Heinz FAULSTICH ${ }^{+}$ \\ * Department of Biological Chemistry. The University of Michigan \\ ANN ARBOR, MICHIGAN 48109 \\ + Department of Chemistry of Natural Products \\ Max Planck Institute for Medical Research \\ HEIDELBERG, HEST GERMANY
}

Received December 5, 1983

SUMMARY. We report here the first case of an affinity isolation of eukaryotic RNA polymerase II. The procedare employs an affinity matrix composed of a-amanitin coupled to Sepharose 4B via a ten atom spacer. RNA polymerase II from either calf thymus or wheat germ binds to the amanitinSepharose, as indicated by subsequent elution with sodium dodecylsulfatecontaining buffer and analysis by polyacrylamide ge1 electrophoresis. The specificity of binding is demonstrated by the fact that when the enzyme is preincubated with $1 \mu \mathrm{g} / \mathrm{m} 1$ of free a-amanitin, subsequent binding to the amanitin-Sepharose is abolished. Elution methods that should permit the recovery of active enzyme from the colum are discussed.

A number of methods for the purification of RNA polymerase II (E.C. 2.7.7.6) have been described (for references see 1,2), a11 of which involve relatively standard ion exchange and gel permeation column chromatography. We report here the first example of an affinity isolation of RNA polymerase II. The affinity adsorbent is composed of Sepharose 4B coupled via a ten a tom spacer arm (3) to a-amanitin, a fungal torin which binds to RNA polymerase II with a high affinity $\left[K_{d} \sim 10^{-9} M\right](4)$. We demonstrate that RNA polymerase II from both calf thymus and wheat germ will bind specifically to amanitin-Sepharose, and that the affinity adsorbent can be used to isolate the enzyme from a partially purified fraction.

\section{MATERIALS AND METHODS}

Amanitin-Sepharose: $0-[5-[$ [ (aminoethy 1)-amino]carbony 1]-pent-1-y1]a-amanitin was synthesized as described (3) and coupled to cyanogen-bromideactivated Sepharose 4B (Faulstich, Zobe1ey, and Trischmann, in preparation). The resultant affinity adsorbent contained 1 mg amanitin/ml Sepharose.

\footnotetext{
$x$ to whom correspondence should be addressed
} ABBREVIATIONS: SDS, sodinm dodecylsulfate 
Incubation conditions: Immediately before use the amanitin-Sepharose was washed with 100 volumes $\mathrm{H}_{2} \mathrm{O}$ by centrifugation. A fina 1 buffer wash was then performed. The binding protocol used for the experimental results shown in Figure 1 is representative of the technique and will therefore be described in detail. Washed amanitin-Sepharose ( $50 \mu 1$ packed volume) was added to $25 \mu \mathrm{g}$ calf thymus RNA polymerase II (5) and $50 \mu \mathrm{g}$ bovine serum albumin in a total volume of $150 \mu 1$ of Buffer TA (50 mM Tris-Cl, $100 \mathrm{mM}$ ammonium acetate, pH 7.9). Incubation was for 1 hr at $0^{\circ} \mathrm{C}$, after which the resin was washed by centrifugation with two $150 \mu 1$ aliquots of Buffer TA. The protein bound to the resin was then eluted by three $150 \mu 1$ washes of $0.2 \%$ sodium dodecyl sulfate (SDS). The el nates were pooled and concentrated to about $50 \mu 1$ by evaporation in a Savant Speed-Vac concentrator and made $10 \%$ in glycerol and $1 \%$ in 2-mercaptoethanol. The samples were then fractionated by SDS poly- acrylamide gel electrophoresis according to the method described by Laemmli (6). To test for specificity of binding, an identical polymerase sample was incubated ( 5 minutes, $0^{\circ} \mathrm{C}$ ) with $1 \mu g / m 1 a-$ amanitin (Boehringer) before being added to the amanitin-Sepharose.

Partially purified wheat germ RNA polymerase II fractions were prepared as described (7). The procedure for binding to amanitin-Sepharose was similar to that described above except that the binding was carried out in TEDG buffer ( $50 \mathrm{mM}$ Tris-HC1, ( $\mathrm{pH} 7.9$ ), $0.1 \mathrm{mM}$ EDTA, $1 \mathrm{mM} \mathrm{DTT,} \mathrm{25 \%} \mathrm{(w/v)}$ ethylene glyco1) p1us $250 \mathrm{mM}$ ammonium sulfate. Also, following incubation the amanitin-Sepharose was washed with Buffer W (50 mM Tris HCl, pH 7.9), $0.1 \mathrm{mM}$ EDTA, $1 \mathrm{mM}$ DTT, 50\% $(\mathrm{w} / \mathrm{v})$ ethylene glycol, $500 \mathrm{mM}$ ammonium sulfate, $0.1 \%$ Brij 35) three times, using twenty times the packed volume of the Sepharose in each wash. The washing was completed with two washes of $1 \mathrm{mM}$ Tris HCl (pH 7.9), after which the bound protein was eluted with $0.2 \%$ SDS as above.

\section{RESULTS AND DISCUSSION}

Figure 1 shows the results of an experiment in which an aliquot of purified calf thymus RNA polymerase II was gently shaken with an aliquot of amanitin-Sepharose, after which the adsorbent was washed several times with buffer and finally eluted with $0.2 \%$ sodium dodecyl sulfate (SDS). The first supernatant (containing the unadsorbed polymerase) as vell as the SDS eluate were then electrophoresed in an SDS-containing polyacrylamide gel. In the gel shown in Figure 1 it can be seen that the channel to which was applied the eluate (Figure 1A) contains heavy RNA polymerase II bands, while the channel to which the first supernatant was applied (Figure 1B) contains considerably 1ighter RNA polymerase bands. Thus the bulk of the polymerase becomes bound to the amanitin-Sepharose, demonstrating that the binding of polymerase to the adsorbent is very efficient.

The results in Figures $1 \mathrm{C}$ and 1D estab1ish that the polymerase is bound to the column specifically, i.e. via the attached amanitin. Here an incubation identical to that described above was performed, only this time 
A $\quad$ B $\quad$ C $\quad$ D

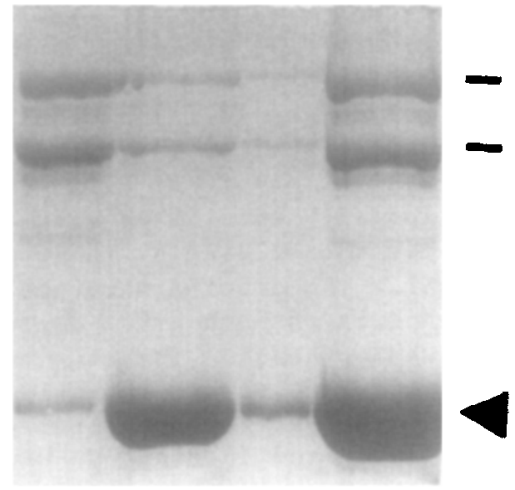

Figure 1. Fractionation of Porified Calf Thymus RNA Polymerase II on

Amanitin-Sepharose. Purified calf thyms RNA polymerase II was preincubated with or without $1 \mu \mathrm{g} / \mathrm{ml}$ a-amanitin and then added to amanitin-Sepharose. After a further incubation, the amanitin-Sepharose was washed with Buffer TA. Bound protein was then eluted from the resin by washing with $0.2 \%$ SDS (see Materials and Methods for details). The entirefirst supernatant as well as the entire SDS eluate were concertrated and then subjected to electrophoresis on a $7.5 \%$ polyacrylamide gel containing SDS. The samples were: A. SDS eluate, preincubation with buffer only. B. First wash supernatant, preincubation with buffer only. C. SDS eluate, preincubation with $1 \mu_{g} / m 1$ a-amanitin. D. First wash supernatant, preincubation with 1 $\mu \mathrm{g} / \mathrm{ml}$ a-amanitin. The lines at the right indicate the mobilities of the two largest subunits of calf thymus RNA polymerase II, while the triangle at the right indicates the mobility of the BSA added as a carrier.

the enzyme was preincubated with $1 \mu g / m 1$ free amanitin. Now it can be seen

that very little RNA polymerase II is bound to the adsorbent fpellet elution, Figure 1C) and virtually all of the polymerase is found in the supernatant (Figure 1D). In contrast, the BSA carrier protein remains in the supernatant regardless of preincubation conditions. Thus the results in Figure 1 establish that the amanitin-Sepharose can be nsed to efficient1y and specifically isolate RNA polymeraso II from a mixture of proteins.

The specificity of binding is further supported by the results in Figures 2 and 3 . Fignre 2 demonstrates that incubation of a sample of partially purified wheat germ RNA polymerase II (Fraction 4 of Jendrisak and Burgess (7), shown in Figure 2D) to amanitin-Sepharose and subsequent SDS elution of the washed resin results in an enzyme that is substantially purified as indicated by comparison to a reference enzyme preparation which was purified by the standard chromatographic method (Figure 2A). Again, 


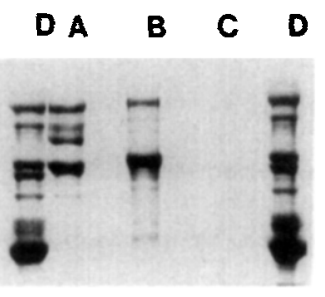

\section{A B $\quad$ C $\quad$ D}

(2)
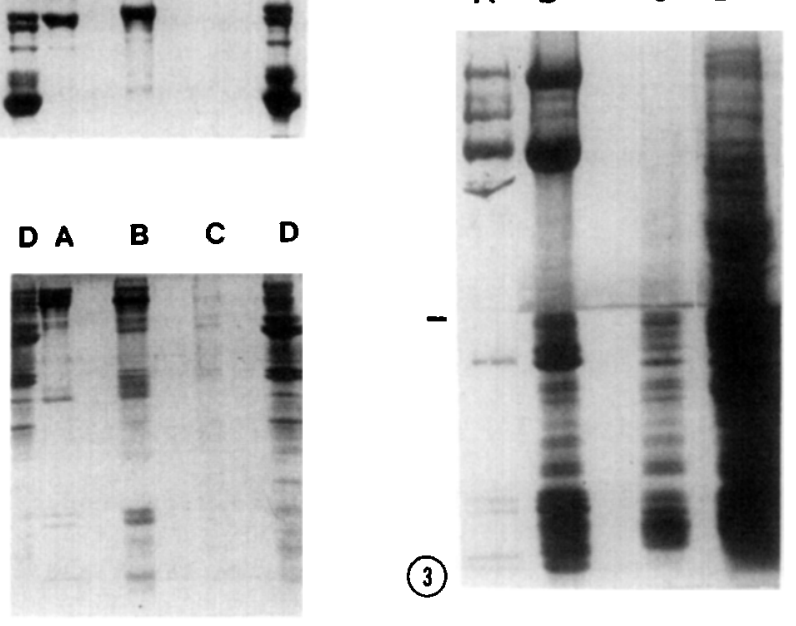

Figure 2. Isolation of theat Germ RNA Polymerase II from a Partia11y Purified Extract by Amanitin-Sepharose. Wheat germ RNA polymerase II was purified through Fraction 4 (Polymin $\mathrm{P}$. $\left(\mathrm{NH}_{4}\right)_{2} \mathrm{SO}_{4}$ precipitation, and DEAEce1lulose chromatography) according to Jendrisak and Burgess (7).

Samples of Fraction 4 were incubated with amanitin-Sepharose with or without a preincubation with $1 \mu \mathrm{g} / \mathrm{ml} \alpha$-amanitin, and the resin as then washed with buffer and finally cluted with $0.2 \%$ SDS (sec Materials and Methods). Samples were then subjected to electrophoresis in a $7.5 \%$ (upper pane1) or 12.5 (Lower panel) polyacrylanide gel in the presence of SDS. Samples are A. Wheat germ RNA polymerase II purified according to the method of Jendrisak and Burgess ( 7 ) (to serve as purified polymerase reference). B. SDS eluate from amanitin Sepharose where the original Fraction 4 was preincubated ith buffer only. C. SDS eluate from amanitin-Sepharose where the original Fraction 4 was preincubated with $1 \mu g / m i$ amanitin. D. Starting Fraction 4.

Figure 3 Isolation Fractionation of Wheat Germ RNA Polymerase II from Fraction, 3 . Fraction 3 of Jendrisak and Burgess (7) was used instead of Fraction 4 as in Figure 2. Electrophoresis was carried out in a composite ge1, 7.5\% acry amide on top and $12.5 \%$ acrylamide bel ow. The bar to the left of the figure indicates the boundary between the two layers. Samples were A. Purified RNA polymerase II reference (c.f. Figure 2A). B. SDS elution from amanitin-Sepharose where the original Fraction 3 was preincubated with buffer only. C. SDS elution from amanitin-Sepharose where the original Fraction 3 was preincubated with $1 \mu \mathrm{g} / \mathrm{ml}$ a-amanitin. D. Starting Fraction 3 ( $0.1 \%$ of the amount applied to amanitin-Sepharose).

preincubation of the Fraction 4 aliquot with $1 \mu \mathrm{g} / \mathrm{ml}$ a-amanitin abolishes polymerase bonding (Figure $2 \mathrm{C}$ ).

Figure 3 shows the results of the use of a less purified fraction of wheat germ as a source of the RNA polymerase for affinity isolation on amanitinSepharose. In this experiment Fraction 3 of Jendrisat and Burgess (7) is used as start material. Fraction 3 is a wheat germ crude extract from which has been removed most of the chromatin by a Polymin P/precipitation-elution 
step, and its protein content is shown in Figure 3D. Figure 3B shows that after incubating Fraction 3 with amanitin-Sepharose (essentially as described above), the SDS eluate is highly enriched for RNA polymerase. Again, all of the polymerase binding is abolished by preincubation of the Fraction 3 with $1 \mu \mathrm{g} / \mathrm{ml}$ amanitin (Figure $3 \mathrm{C}$ ). Comparing densitometer traces of lanes $B$ and $C$ of Figure 3 , the RNA polymerase II in the eluate can be estimated to be about $60 \%$ pare, representing a purification of about 100 fold (cf. reference 7). Figure 3 al so show that while the reference polymerase preparation (Figure $3 A$ ) purified by standard chromatographic techniques contains significant amounts of degradation products (8) of the largest subunit (the two bands immediately beneath the highest band in Figure $3 A$ ), the affinity-purified enzyme contains by comparison only minor amounts of these components.

The results in Figures 1,2 , and 3 demonstrate that amanitin-Sepharose can be employed as an efficient and specific affinity adsorbent for RNA polymerase II. This is the first description of an affinity chromatographic isolation of this enzyme. However, a significant problem with the use of the amanitin-Sepharose as described is the amount of non-specific binding, which is indicated by the amount of the protein eluted from the resin after incubation with a sample containing excess free amanitin (Figures 1C, $2 \mathrm{C}$ and 3C). The presence of this protein in the eluate is probably due to a large extent to the harsh non-specific elution conditions ( $0.2 \%$ SDS) used. It would clearly be preferable to use the classical affinity chromatographic method of specifically eluting with free ligand, i.e. excess a-amanitin. We have tried such a specific elution, but so fax our attempts have not been successful. The likely explanation for this failure is the fact that the half time of release of a-amantin from RNA polymerase II is on the order of days (4).

The search for a specific elution method has led us to investigate the use of photoelution. The plausibility of the photoelution method was 
suggested by our earlier observation (9) that amanitin-inhibited RNA polymerase II can be photoreactivated by specifically destroying the amanitin $\underline{\text { in sitn }}$ via exposure to monochromatic $314 \mathrm{~nm}$ irradiation, a wavelength which is absorbed by amanitin but not by polymerase. Preliminary results indicate that 314 m irradiation of a slurry of amanitin-Sepharose carrying bound polymerase does indeed elute the polymerase. Such a photoelution technique has the following advantages: 1.) the elution method is specific for RNA polymerase II bound to amanitin, which should resolt in the eluted protein being substantially purer than that eluted by the nonspecific $(0.2 \%$ SDS) method; 2.$)$ the eluted protein should not only be structurally intact but enzymatically active (9) as well.

There are a number of immediate applications for the amanitinSepharose. It can be used to quickly isolate and identify the subunit composition of RNA polymerase II from tissues or cell lines for which the polymerase has not yet been characterized. This should be particularly effective if samples are applied with and without amanitin preincubation and the eluates analyzed by two dimensional electrophoresis (e.g. reference 8). The amanitin-Sepharose should also prove to be especially useful for rapid purification of RNA polymerase II, particularly when the photoelution method described above is perfected. Furthermore, studies which require that endogenons RNA polymerase II be specifically removed from an extract $(10,11)$ so that defined polymerase can be added back (e.g. transcription stadies) would benefit from this adsorbent.

Final1y, we are employing the amanitin-Sepharose in our studies of transcribing chromatin. We are using it to develop a technique by which transcribing chromatin can be isolated by binding it to amanitin-Sepharose via its RNA polymerase II. Once isolated the transcribing chromatin will be characterized and compared with inactive chromatin. Thas amanitinSepharose should prove to be particularly useful in chromatin structure studies as well. 


\section{ACKNOREDGMENTS}

This research was supported by grants from the National Institutes of Heal th

(GM27117) and the American Cancer Society (JRFA-40, M-185).

\section{REFERENCES}

1. Paule, M.R. (1981) TIBS $6,128-131$

2. Lew is, M.K. and Burgess, R.R. (1982) in The Enzymes (Boyer, H., ed.) Vo1. 15, pp. 109-53,3 rd od., Academic Press, New York

3. Faulstich, H., Trischmann, H., Wieland, Th., Wulf, E. (1981) Biochemistry 20, 6498-6504

4. Cochet-Moilhac, M., and Chambon, P. (1974) Biochem. Biophys. Acta 353, 160-184

5. Hodo, H.G., and B1atti, S.P. (1977) Biochemistry 16, 2334-2343

6. Laommli, O.K. (1970) Nature 227, 680-685

7. Jendrisak, J.J, and Burgess, R,R. (1975) Blochemistry 14, 46394645

8. Guilfoyle, T.J., and Jendrisak, J.J. (1978) Biochemistry 17, 18601866

9. Lutter, L.C. (1982) J. Bio1. Chem. 257, 1577-1578

10. Weil, P.A., Luse, D.S., Segall, J., and Roeder, R.G. (1979) Cell 18, 469-484

11. Manley, J.L., Fire, A., Cano, A., Sharp, P.A., and Gefter, M.L. (1980) Proc. Nat. Acad. Sci. USA 77, 3855-3859 